Radiation Damage Effects on the Magnetic Properties of

$\mathrm{Pu}(1-\mathrm{x}) \operatorname{Am}(\mathrm{x})(\mathrm{x}=0.224)$

S. K. McCall, M. J. Fluss, B. W. Chung, M. W. McElfresh, R. G. Haire

December 19, 2006

Materials Research Society Fall Meeting Boston, MA, United States

November 26, 2006 through November 30, 2006 
This document was prepared as an account of work sponsored by an agency of the United States Government. Neither the United States Government nor the University of California nor any of their employees, makes any warranty, express or implied, or assumes any legal liability or responsibility for the accuracy, completeness, or usefulness of any information, apparatus, product, or process disclosed, or represents that its use would not infringe privately owned rights. Reference herein to any specific commercial product, process, or service by trade name, trademark, manufacturer, or otherwise, does not necessarily constitute or imply its endorsement, recommendation, or favoring by the United States Government or the University of California. The views and opinions of authors expressed herein do not necessarily state or reflect those of the United States Government or the University of California, and shall not be used for advertising or product endorsement purposes. 


\begin{abstract}
$\mathrm{Pu}(\mathrm{Am})$ is stable in the fcc $\delta$-phase from a few atomic percent to nearly 80 atomic percent Am, expanding the average interatomic separation as the alloy concentration of Am increases. Both $\mathrm{Pu}$ and Am spontaneously decay by $\alpha$-emission creating selfdamage in the lattice in the form of vacancy-interstitial pairs and their aggregates. At sufficiently low temperatures, the damage is frozen in place, but can be removed by thermal annealing at sufficiently high temperatures, effectively resetting the system to an undamaged condition. The magnetic susceptibility and magnetization are observed to increase systematically as a function of accumulated damage in the fcc $\delta$ - $\mathrm{Pu}_{1-\mathrm{x}} \mathrm{Am}_{\mathrm{x}}$ $(x=0.224)$. Some results of these observations are reported here.
\end{abstract}

\title{
INTRODUCTION
}

Plutonium-americium alloys present an interesting material for the study of $5 \mathrm{f}$ electron systems, as the two metals form a single stable fcc phase over a wide range of compositions, with the lattice parameter increasing with Am concentration, showing a positive deviation from Vegard's law. Previous work on radiation damage in PuAm alloys has investigated the consequence of damage accumulation on magnetic susceptibility where the damage was accumulated near room temperature $[1,2]$. Recent work[3] on isochronal annealing of PuAm alloys accumulated damage at low temperature with the total number of $\alpha$-decays per atom approximately 20 times smaller than the room temperature work but the accumulated damage (surviving atomic displacements) was much greater. The isochronal annealing study finds that room temperature is very close to the annealing stage where small vacancy clusters are unstable, removing the last magnetically observable indication of radiation damage. Therefore, "damage" accumulated for extended periods of time at room temperature is not simply the very dilute remnant evolution of the vacancy and interstitial displacements and their diffusion history, but likely reflects also the presence of the helium and daughter products of the nuclear decay itself. The present work reports details of low temperature damage accumulation studies and compares these results to the earlier work.

One difference of this experiment compared to the earlier work on PuAm alloys is that the less radioactive Am-243 isotope ( $t_{1 / 2}=7,370$ years) was used instead of the higher activity Am-241( $\mathrm{t}_{1 / 2}=432$ years). As a comparison, the Am-243 isotope has slightly less than three times the activity of Pu-239 ( $\mathrm{t}_{1 / 2}=24,400$ years $)$. Both isotopes of Am decay by spontaneous alpha emission, but the Am-241 decays to the far more stable Np-237 ( $\mathrm{t}_{1 / 2}$ $=2,140,000$ years) so while concentrations of this isotope build up in the specimen over time, they are not likely to contribute appreciably to the magnetic susceptibility ${ }^{*}$. By contrast, Am-243 decays to Np-239 ( $\mathrm{t}_{1 / 2}=2.2$ days) which then decays by beta emission to $\mathrm{Pu}-239$, so no significant quantities of $\mathrm{Np}$ will develop.

Radioactive decay $\mathrm{Pu}(\mathrm{Am})$ proceeds by emission of a $\sim 5 \mathrm{MeV}$ alpha particle and corresponding $86 \mathrm{KeV} \mathrm{U}$ recoil ( $84 \mathrm{KeV} \mathrm{Np}$ recoil). Based on molecular dynamic calculations in $\delta-\mathrm{Pu}[4]$, the alpha particle travels $\sim 10 \mu \mathrm{m}$ losing most of its energy to the electrons, but near the end of its path generates a few hundred Frenkel pairs while the recoiling nucleus generates a much more dense cascade of $\sim 2500$ vacancy and interstitial 
pairs, most of which recombine in the following few hundred nanoseconds. At low temperatures, 10-30 percent of the vacancies and interstitials are expected to survive, effectively becoming frozen in place. This is an important distinction from previous studies that investigated radiation damage accumulated near room temperature, where the cascades continue to evolve after creation because the temperature is high enough to allow activation of both interstitial and vacancy transport.

The accumulated radiation damage results in an excess magnetic susceptibility with explicit temperature dependence indicative of moment formation. Consistent with this observation are low temperature isothermal magnetization studies that show the excess contribution increases monotonically with increasing applied magnetic field. Subsequent thermal annealing restores the system to an undamaged state, and this is reflected in the magnetic properties which return to their initial values, confirming that the decay products are not a significant factor in the results.

\section{EXPERIMENTAL TECHNIQUE}

Specimens of 20-40 $\mathrm{mg}$ are dip coated in a layer of polyimide $\sim 5-15$ microns thick and then mounted on a brass rod the middle of a specially designed cartridge brass sample holder $20 \mathrm{~cm}$ long, shown in Fig. 1, which is then mounted in a commercial SQUID magnetometer (Quantum Design MPMS-5). Cartridge brass was selected because of the low concentration of magnetic impurities, and after machining the sample holder was rinsed in $1 \mathrm{M} \mathrm{HCl}$ to remove any surface iron impurities. Since the magnetometer makes use of a second-order gradiometer, a sample holder that is uniform and long relative to the sensing coil separation should not generate an appreciable signal in the magnetometer. Measurements of the empty holder show negligible response, with the overall contribution on the order of $1 \%$ of the sample signal. The sample is hermetically sealed using a gold O-ring under 1 atmosphere He gas at room temperature, thus providing a second layer of sample encapsulation. The helium exchange gas and brass sample support rod provide excellent thermal grounding for radioactive samples.

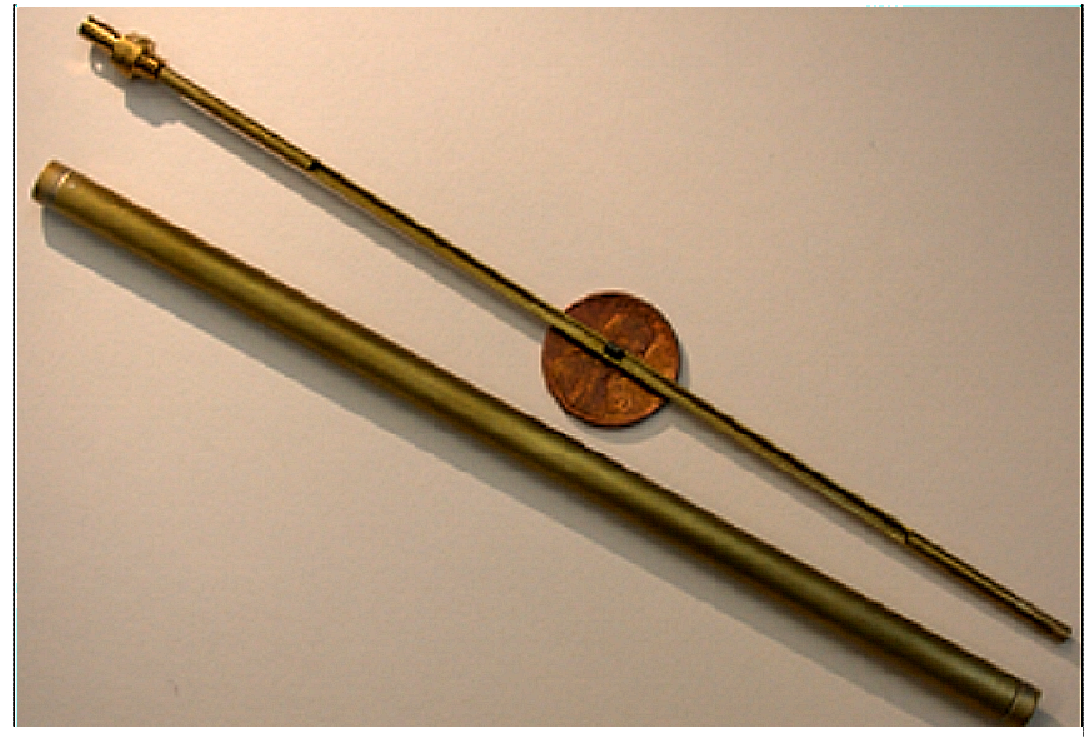

Figure 1: Sample holder with $21 \mathrm{mg}$ sample coated in polyimide and mounted on inner tube. 
Experiments performed using a resistance heater and thermometer in place of the sample show even at $2 \mathrm{~K}$ the difference between the sample temperature and instrument temperature is less than $0.05 \mathrm{~K}$ for an equivalent $50 \mathrm{mg} \mathrm{Pu}-239$ sample. During the measurement process, samples are measured repeatedly at each temperature for several minutes, and there is no systematic drift in the magnetic response that might suggest the sample is not in thermal equilibrium with its surroundings.

\section{RESULTS}

The magnetic susceptibility of the sample, defined as $\mathrm{M} / \mathrm{H}$, is shown as a function of temperature after annealing at $350 \mathrm{~K}$ for 1 hour in Fig. 2. In this sample there is a low temperature Curie tail, likely due to non-actinide impurities known to be present in the sample at the level of a few hundred ppm. At higher temperatures the sample shows weak temperature dependence, but clearly the dominant contribution is temperature independent. This temperature independent term arises from the Van Vleck susceptibility from the filled $j=5 / 2$ shell of the Am atoms[5], along with a Pauli contribution from the conduction bands. Previous work has measured the Am contribution at 780-880 $\mu \mathrm{emu} / \mathrm{mol}-\mathrm{Am}[5]$. Assuming the temperature independent contribution is $\sim 600$ $\mu \mathrm{emu} / \mathrm{mol} \mathrm{PuAm}$, then a simple subtraction of the Am contribution results in a value of $\sim 540 \mu \mathrm{emu} / \mathrm{mol}-\mathrm{Pu}$, which is slightly enhanced when compared to literature values for $\delta$ - $\mathrm{Pu},[6,7]$ of $\sim 500 \mu \mathrm{emu} / \mathrm{mol}-\mathrm{Pu}$, and consistent with earlier results on PuAm alloys[1].

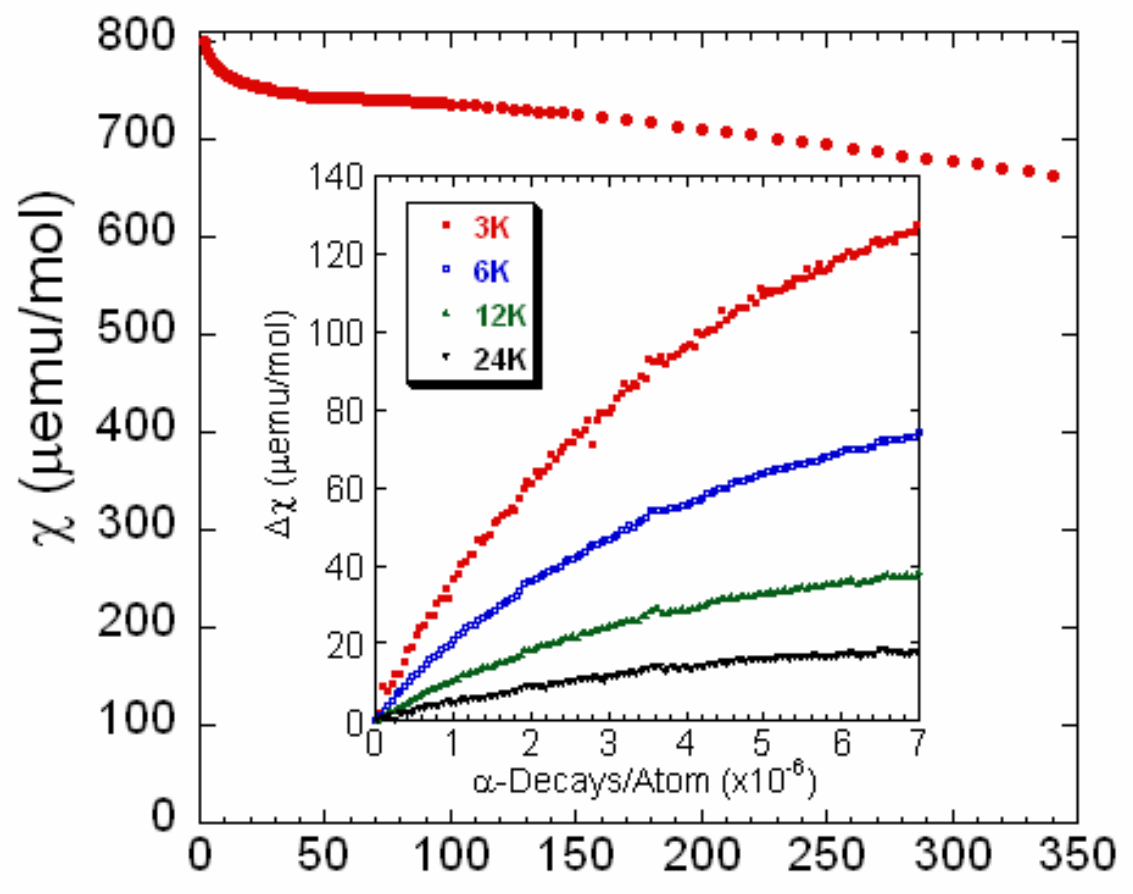

Temperature (K)

Fig. 2 Magnetic susceptibility of the annealed specimen. The inset shows the change in magnetic susceptibility as a function of accumulated damage for several representative temperatures. 


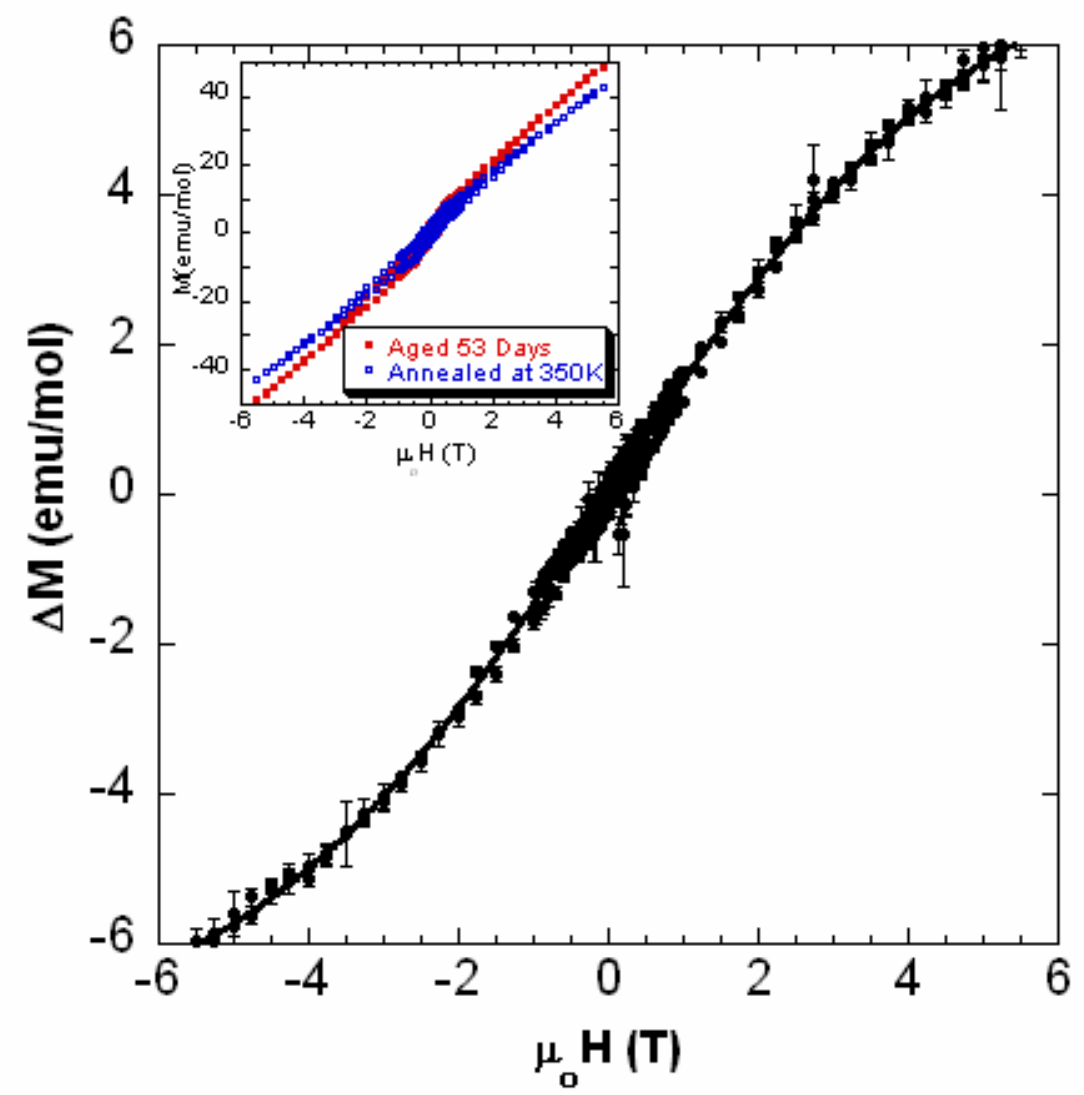

Fig. 3 The inset shows $\mathrm{M}(\mathrm{H})$ for both the freshly annealed specimen (blue) and the specimen aged 53 days at low temperatures. The main figure shows the difference between the two measurements, which has been fit to a Brillouin function as indicated by the line.

Accumulation of radiation damage at low temperatures produces a systematic increase in the magnetic susceptibility of this material in a manner similar to recent work on both $\alpha-\mathrm{Pu}$ and $\delta$-Pu stabilized by $4.3 \mathrm{at} \% \mathrm{Ga}[7]$. In this study, the specimen was maintained at $\mathrm{T}<30 \mathrm{~K}$ with the temperature systematically cycled from $2-30 \mathrm{~K}$. The inset of Fig. 2 shows the results of this measurement where the absolute change in the magnetic susceptibility is plotted as a function of the number of $\alpha$-decays (time) for several characteristic temperatures. The magnetic susceptibility increases monotonically with damage, and is generally consistent with the results obtained on self-damage studies of $\alpha$ - and $\delta$-Pu.

The effect of the accumulated damage is also observed in the isothermal magnetization, as shown in Fig. 3. The inset of this figure shows $\mathrm{M}(\mathrm{H})$ curves taken at $3 \mathrm{~K}$ for $-5.5 \mathrm{~T} \leq \mu_{\mathrm{o}} \mathrm{H} \leq 5.5 \mathrm{~T}$ for the same sample when freshly annealed and after aging below $30 \mathrm{~K}$ for 53 days $\left(8.3 \times 10^{-6} \alpha\right.$-decays/atom). The main figure shows the difference between these two measurements, reflecting the change in the magnetization due to selfdamage. The magnetization increases monotonically, and can be fit to a Brillouin function as expected for a system with developing magnetic moments. As an example, using a Lande $\mathrm{g}$ factor of 2 , and $\mathrm{J}=1 / 2$ results in the fit shown in Fig. 3 with a saturation magnetization of $1.25 \times 10^{-3} \mu_{\mathrm{B}} /$ atom, or $\sim 150 \mu_{\mathrm{B}} / \alpha$-decay. 


\section{CONCLUSIONS}

Low temperature damage accumulation experiments on $\operatorname{Pu}_{1-\mathrm{x}} \mathrm{Am}_{\mathrm{x}}(\mathrm{x}=0.22)$ alloy show an appreciable increase in both the magnetic susceptibility and isothermal magnetization. The excess magnetic susceptibility has a temperature dependence consistent with Curie-Weiss behavior, suggesting that the self-damage reflects the evolution of local moments in the alloy. The magnetization shows indications of Brillouin behavior further supporting developing local moments.

\section{ACKNOWLEDGEMENTS}

This work was performed under the auspices of the U.S. Department of Energy by the University of California Lawrence Livermore National Laboratory under Contract No W-7405-Eng-48.

\section{REFERENCES}

*Early work on the magnetic properties of Am-241 found a low temperature upturn in the magnetic susceptibility. It was suggested that this resulted from $\mathrm{Np}-237$ growing into the sample from $\alpha$-decay of Am-241[8] Later work comparing Am-241 with Am-243 samples showed similar low temperature upturns in the susceptibility for both, indicating that such low temperature upturns are a result of defects or other impurities[9].

[1] M. Dormeval, Ph.D. thesis, Universite de Bourgogne, 2001

[2] N. Baclet, M. Dormeval, P. P, J. M. Fournier, F. Wastin, E. Colineau, J. Rebizant, and G. H. Lander, J. Nucl. Sci. Technol. Suppl. 3, 148 (2002).

[3] S. K. McCall, M. J. Fluss, B. W. Chung, M. W. McElfresh, G. F. Chapline, and D. D. Jackson, Forthcoming Article in J. Alloys Compd. (2007).

[4] B. D. Wirth, A. J. Schwartz, M. J. Fluss, M. J. Caturla, M. A. Wall, and W. G. Wolfer, MRS Bulletin 26, 679 (2001).

[5] B. Kanellakopulos, A. Blaise, J. M. Fournier, and W. Muller, Solid State Commun. 17, 713 (1975).

[6] J. C. Lashley, A. Lawson, R. J. McQueeney, and G. H. Lander, Phys. Rev. B 72, 054416 (2005).

[7] S. K. McCall, M. J. Fluss, B. W. Chung, M. W. McElfresh, D. D. Jackson, and G. F. Chapline, PNAS 103, 17179 (2006).

[8] B. D. Dunlap, M. B. Brodsky, G. M. Kalvius, and G. K. Shenoy, in Plutonium 1970 and Other Actinides, Nuclear Metals 17, edited by W. N. Miner (Metall.Soc. and Amer. Inst. Mining, 1970), p. 331.

[9] M. B. Brodsky, Rep. Prog. Phys. 41, 1547 (1978). 